Gut, 1981, 22, 149-152

\title{
Autoimmunity to a liver membrane lipoprotein and liver damage in alcoholic liver disease
}

\author{
A PERPERAS, D TSANTOULAS, B PORTMANN, A L W F EDDLESTON, \\ AND R WILLIAMS
}

The Liver Unit, King's College Hospital and Medical School, London

SUMMARY Antibodies reacting with a liver membrane lipoprotein (LSP) have been detected by radioimmunoassay in the sera of $15(27 \%)$ of 55 patients with alcohol-related liver lesions. There was a close association between the presence of the anti-LSP antibody and the finding on liver biopsy of a lymphocytic infiltrate in the portal tracts together with piecemeal necrosis of periportal hepatocytes. These histological features are characteristically found in the autoimmune disorder of chronic active hepatitis, in which anti-LSP antibodies are almost invariably present. It is suggested that in these cases of alcoholic liver disease there is loss of tolerance, and continued production of anti-LSP could promote periportal inflammation and accelerate the progression to cirrhosis. In the cases of acute alcoholic hepatitis without periportal inflammation studied, anti-LSP was not detected demonstrating that production of this autoantibody is not simply secondary to liver damage.

Many mechanisms have been proposed to explain the development of liver damage in patients with a high alcohol intake. Although experimental studies in man and baboons have shown that alcohol itself may be directly damaging to liver cells, ${ }^{1}$ epidemiological evidence suggests that only $30 \%$ of heavy drinkers develop alcoholic hepatitis and $10 \%$ cirrhosis, ${ }^{2}$ and other factors must determine the individual variation in the histopathological response. An increasing number of investigations have shown that potentially tissue-damaging immune responses accompany alcoholic liver injury. ${ }^{3}$

In one study, peripheral blood lymphocytes from patients with cirrhosis and acute alcoholic hepatitis were found to be cytotoxic to isolated rabbit hepatocytes. ${ }^{4}$ The reaction was shown to be mediated by non-T lymphocytes and could be blocked by the addition of small amounts of a liver membrane lipoprotein (LSP). ${ }^{4}$ One explanation for these findings is that the cytotoxicity was mediated, as in other types of autoimmune liver disease, by an antibodydependent, cell-mediated mechanism with antibody to LSP playing a major role in determining the specificity. ${ }^{5}$ In the present study a sensitive and specific radioimmunoassy has been used to investigate the frequency of anti-LSP antibodies in alcoholic liver disease and the relationship between the

Received for publication 16 October 1980 presence of this antibody and particular histological features in 55 patients with a wide range, both in severity and in type, of alcohol-related liver lesions.

\section{Methods}

\section{PATIENTS}

All 55 patients investigated had an alcohol intake greater than $80 \mathrm{~g} /$ day. Forty-eight of them represented consecutive admissions with alcohol-related liver disease to the Liver Unit over a period of six months. To ensure that the full range of histopathological responses to alcohol was covered, seven additional cases with fatty change alone or inactive cirrhosis were selected from patients attending a follow-up clinic.

Liver histology was available in all cases either from needle biopsy or subsequently at necropsy and serum samples were obtained within two weeks of the time of biopsy. Each biopsy was examined by one of us (BP), without knowledge of the immunological findings, and assessed for the presence and intensity (grade 0 absent, 1 mild, 2 moderate, and 3 severe) of each of the following histological features: fatty change, portal tract mononuclear infiltrate and piecemeal necrosis of periportal hepatocytes, hyaline inclusions, spotty lobular necrosis and polymorphonuclear infiltration, and cirrhosis. From the resultant scores it was possible to classify each biopsy into one 
of six categories: fatty liver alone, alcoholic hepatitis, alcoholic hepatitis plus inactive cirrhosis-that is, with minimal portal mononuclear infiltrate and no piecemeal necrosis-alcoholic hepatitis plus active cirrhosis, active cirrhosis without alcoholic hepatitis, and inactive cirrhosis.

\section{RADIOIMMUNOASSAY FOR ANTI-LSP}

ANTIBODIES

This is described in detail elsewhere. ${ }^{6}$ Serum samples were coded and examined for anti-LSP antibodies without knowledge of the histological findings. Each diluted one in 20 in $0.1 \mathrm{M}$ barbitone buffer, $\mathrm{pH} 8.5$ with $1 \%$ bovine albumin and $25 \mu \mathrm{l}$ samples incubated in triplicate for three hours at $4^{\circ} \mathrm{C}$ with $25 \mu \mathrm{l}(2.5 \mathrm{ng})$ of a purified preparation of human LSP previously radiolabelled with ${ }^{125} \mathrm{I}$. Staphylococcal clumping factor (Sigma), $0 \cdot 1 \mathrm{ml}$, was then added to facilitate the precipitation of IgG- ${ }^{125}$ I LSP immune complexes and incubation continued for a further hour at $4^{\circ} \mathrm{C}$. $0.85 \mathrm{ml}$ barbitone/albumin buffer was then added and the mixture centrifuged at $20000 \times g$ for five minutes. $0.5 \mathrm{ml}$ of the supernatant was removed and this and the remainder of the incubation mixture (including the pellet) counted separately. The per-

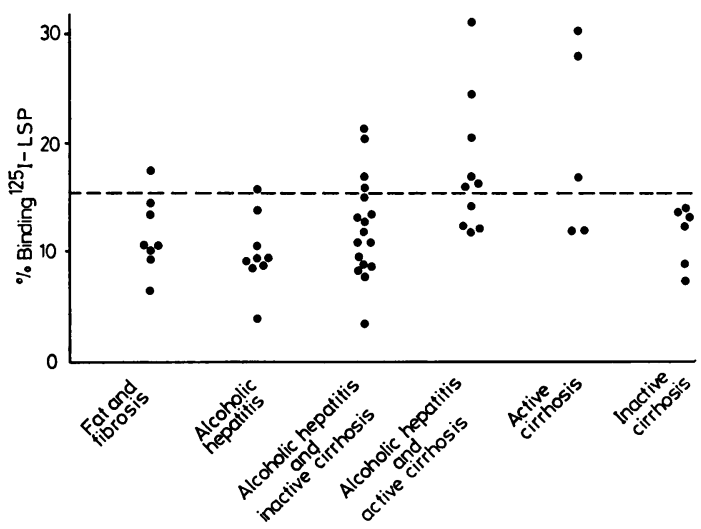

Figure Percentage ${ }^{125}$ I LSP bound by sera from the 55 patients with alcoholic liver disease divided into groups according to the histological appearances on liver biopsy. The dotted line indicates the upper limit of the normal range. centage binding of ${ }^{125} \mathrm{I}$-LSP was then calculated using the following formula:

$$
\% \text { binding }=\frac{\text { cpm remainder }- \text { cpm upper } 0.5 \mathrm{ml}}{\text { cpm remainder }+ \text { cpm upper } 0.5 \mathrm{ml}} \times 100
$$

A normal range was established from the results obtained using 20 control sera from healthy blood donors shown to be negative for HBsAg and antiHBs. The mean \% binding of LSP by these samples was $9 \cdot 3$ with a standard deviation of $2 \cdot 1$, giving an upper limit of the normal range (mean $+3 \mathrm{SD}$ ) of $15.6 \%$. Values above this level were assumed to reflect the presence of anti-LSP antibodies in the serum under test, an assumption validated in previous specificity studies. ${ }^{6}$

\section{Results}

Anti-LSP antibodies were detected in sera from 15 $(27 \%)$ of the 55 cases tested. Analysis of the results. in relation to the categories of disease as defined histologically showed striking differences in the frequency of anti-LSP in the different groups. The antibody was detected most often in sera from cases with active cirrhosis with or without alcoholic hepatitis $(60 \%$ and $60 \%$ respectively) and was only found in one $(11 \%)$ of the nine patients with acute alcoholic hepatitis alone and none of the six with inactive cirrhosis (Figure). This finding would suggest a close association between anti-LSP and periportal inflammatory activity (mainly found in, and characteristic of, active cirrhosis) and this was confirmed when the findings were related to the presence or absence of individual histological features (Table). Thus, anti-LSP was detected in $\mathbf{1 0}$ $(56 \%)$ of 18 patients whose biopsies showed a portal mononuclear infiltrate with piecemeal necrosis of periportal hepatocytes, but in only five $(14 \%)$ of the remaining 37 cases $\left(\chi^{2} 10.8, \quad P<0.005\right)$. Weaker associations, which were not statistically significant, with alcoholic hyaline and cirrhosis probably reflected the tendency for both these lesions to be associated with periportal inflammation.

As individual histological features had been scored with respect to their severity, it was also possible to examine the relationship between the frequency of anti-LSP antibodies in serum and the

Table Anti-LSP and histological features on liver biopsy in alcoholic liver disease

\begin{tabular}{|c|c|c|c|c|c|c|c|c|c|c|c|c|}
\hline & \multicolumn{3}{|c|}{ Periportal activity } & \multicolumn{3}{|c|}{ Lobular inflammation } & \multicolumn{3}{|c|}{ Hyaline inclusions } & \multicolumn{3}{|c|}{ Fatty change } \\
\hline & & \multicolumn{2}{|c|}{ Anti-LSP } & & \multicolumn{2}{|c|}{ Anti-LSP } & & \multicolumn{2}{|c|}{ Anti-LSP } & & \multicolumn{2}{|c|}{$A n t i-L S P$} \\
\hline & & (no.) & $(\%)$ & & (no.) & $(\%)$ & & (no.) & $(\%)$ & & (no.) & $(\%)$ \\
\hline $\begin{array}{l}\text { Absent } \\
\text { Present }\end{array}$ & $\begin{array}{l}37 \\
18\end{array}$ & $\begin{array}{r}5 \\
10\end{array}$ & $\begin{array}{l}14 \\
56\end{array}$ & $\begin{array}{r}9 \\
46\end{array}$ & $\begin{array}{r}3 \\
12\end{array}$ & $\begin{array}{l}33 \\
26\end{array}$ & $\begin{array}{l}21 \\
34\end{array}$ & $\begin{array}{r}4 \\
11\end{array}$ & $\begin{array}{l}19 \\
32\end{array}$ & $\begin{array}{l}11 \\
44\end{array}$ & $\begin{array}{r}2 \\
13\end{array}$ & $\begin{array}{l}18 \\
30\end{array}$ \\
\hline
\end{tabular}


intensity of each histological lesion. The results again underlined the specificity of the association between anti-LSP and portal and periportal inflammation. In the majority of those patients with this histological feature, the lesion was mild and anti-LSP was detected in $50 \%$. Two cases had a moderate lymphocytic portal infiltrate with piecemeal necrosis of periportal hepatocytes and anti-LSP was present in both. None of the patients had severe periportal changes, comparable with those found in most patients with chronic active hepatitis.

There was no significant association between antiLSP antibodies and abnormalities in any of the standard biochemical tests of liver function, including serum levels of aspartate transaminase, alkaline phosphatase, gamma glutamyl transpeptidase, and bilirubin, or with total globulin, individual immunoglobulins, or autoantibodies reacting with smooth muscle or nuclear antigens. There was no significant difference in the sex ratio between those with and those without anti-LSP in the serum.

\section{Discussion}

The most striking finding in the present study is the close association between the presence of anti-LSP antibodies in serum and the histological features of portal and periportal lymphocyte infiltration together with piecemeal necrosis of periportal hepatocytes. In our previous study of lymphocyte cytotoxicity to rabbit hepatocytes in patients with alcoholic liver disease, there was also a close correlation between the presence of cytotoxic lymphocytes and portal and periportal inflammation. ${ }^{4}$ In contrast with the results of the present study a significant correlation with histological features of alcoholic hepatitis was also found, but all but two of those patients had cirrhosis and a separate group with acute alcoholic hepatitis alone were not studied. Nine such patients were investigated in the present study and anti-LSP antibodies were detected in only one. This argues against the possibility that an antiLSP response is simply a reflection of liver cell damage, and additional evidence against such a view is the lack of any correlation between the presence of anti-LSP and serum aspartate aminotransferase levels.

Detailed analysis of the relationship between antiLSP antibodies and histological appearances in liver tissue have now been reported by us in three conditions-chronic active hepatitis, ${ }^{\text {? }}$ primary biliary cirrhosis, ${ }^{8}$ and alcoholic liver disease. In all three there is a close relationship between the presence of this autoantibody and portal and periportal lymphocyte infiltration with piecemeal necrosis. Thus, antiLSP, although not disease specific, was seen to be 'lesion specific' and, as similar histological features can be induced in rabbits by immunisation with human liver fractions containing LSP, ${ }^{9}$ it seems increasingly likely that immune responses to antigen(s) in the LSP preparation are the cause, rather than the result, of periportal liver cell necrosis.

It is now clear that there are several antigenic determinants within the LSP preparations,${ }^{10-12}$ one of which is liver specific but species cross-reactive, a second which may be liver and species specific, and possibly a third which cross-reacts with a component in other tissues. ${ }^{13}$ All LSP determinants seem to be present in or on the hepatocyte membrane and controlled fragmentation of the cell membrane or the LSP complex followed by isolation of the relevant components will be necessary before the specificity of the anti-LSP response in different liver diseases can be analysed in detail.

The immunological interactions which lead to the production of anti-LSP antibodies in association with increased alcohol intake are unclear. In acute viral hepatitis high titres of anti-LSP are found during the acute stages and persist in those showing progression to chronic liver disease. ${ }^{7}$ A similar autoimmune response may in some patients be triggered by acute alcoholic hepatitis, and if this continues the resulting piecemeal necrosis could favour the development of cirrhosis. Inactive cirrhosis could represent a terminal stage in which immune reactivity becomes depressed as a consequence of the cirrhotic process, but another possibility is that the cirrhosis in these cases developed directly from a preceding alcoholic hepatitis without triggering any autoimmune response. Serial studies documenting the changes in immune responses to alcohol-altered and self antigens over prolonged periods in patients with varying degrees of liver damage and alcohol intake will clearly be of considerable importance in clarifying the pathogenetic mechanisms determining the progression to cirrhosis.

This study forms part of a research programme in alcoholic liver disease and autoimmune liver damage supported by the Department of Health and Social Security, the Wellcome Trust, and the Brewers Society.

\section{References}

${ }^{1}$ Lieber CS, De Carli LM, Rubin E. Sequential production of fatty liver, hepatitis and cirrhosis in sub-human primates fed ethanol with adequate diets. Proc Nat Acad Sci 1975; 72: 437-41.

${ }^{2}$ Galambos JT. Alcoholic hepatitis. In: Schaffner F, Sherlock S, Leevy CM, eds. The liver and its diseases. New York: Intercontinental Medical Book, 1974: 255-67. 
${ }^{3}$ Leevy CM, Kanagasundaram N, Matsumoto K, Chen T. In: Eddleston ALWF, Weber JCP, Williams R, eds. Immune reactions in liver disease. Tunbridge Wells: Pitman Medical, 1979: 195-207.

${ }^{4}$ Cochrane AMG, Moussouros A, Portmann B, McFarlane IG, Thomson AD, Eddleston ALWF, Williams R. Lymphocyte cytoxicity for isolated hepatocytes in alcoholic liver disease. Gastroenterology 1977; 72: 918-23.

${ }^{5}$ Cochrane AMG, Moussouros A, Thomson AD, Eddleston ALWF, Williams R. Antibody-dependent cell mediated ( $\mathrm{K}$ cell) cytoxicity against isolated hepatocytes in chronic active hepatitis. Lancet, 1976; 1: $441-4$.

${ }^{6}$ Jensen DM, McFarlane IG, Eddleston ALWF, Williams R. The development of a radioimmunoassay for the detection of antibodies to a liver-specific membrane lipoprotein (LSP). J Clin Lab Immunol 1978; 1: 31-6.

${ }^{7}$ Jensen DM, McFarlane IG, Portmann B, Eddleston ALWF, Williams R. Detection of antibodies directed against a liver specific membrane lipoprotein in patients with acute and chronic active hepatitis. $N$ Engl J Med 1978; 299: 1-7.

${ }^{8}$ Tsantoulas D, Perperas A, Portmann B, Eddleston ALWF, Williams R. Antibodies to a human liver membrane lipoprotein (LSP) in primary biliary cirrhosis. Gut 1980; 21: 557-60.

${ }^{9}$ Meyer zum Buschenfelde KH, Kossling FK, Miescher PA. Experimental chronic active hepatitis in rabbits following immunisation with human liver proteins. Clin exp Immunol 1972; 11: 99-108.

${ }^{10} \mathrm{McFarlane}$ IG, Wojcicka BM, Williams R. Antigens of the human liver. Clin exp Immunol 1980; 40: 1-7.

${ }^{11}$ Chisari FV. Liver specific protein in perspective. Gastroenterology 1980; 78: 168-70.

${ }^{12}$ Hutteroth TH, Meyer zum Buschenfelde KH. Clinical relevance of the liver specific lipoprotein (LSP). Acta Hepato-Gastroenterol 1978; 25: 243-53.

${ }^{13}$ Behrens UJ, Paranetto F. Studies on 'liver specific' antigens. In: Evaluation of the liver specificity of 'LSP' and 'LP'. Gastroenterology 1979; 77: 1045-52. 